\title{
Research Paper \\ The Efficacy of Early Pathways Program on Parent-Child Interaction and Warmth
}

\author{
Hannaneh Panahipour ${ }^{1} \odot$, Simin Hosseinian ${ }^{2} \odot$, Sogand Ghasemzadeh ${ }^{3} \odot$
}

1. MA., Department of Counseling, Faculty of Educational Sciences and Psychology, Alzahra University, Tehran, Iran.

2. Professor, Department of Counseling, Faculty of Educational Sciences and Psychology, Alzahra University, Tehran, Iran.

3. Assistant Professor, Department of Psychology \& Education of Exceptional Children, Faculty of Psychology and Educational Sciences, University of Tehran, Tehran, Iran

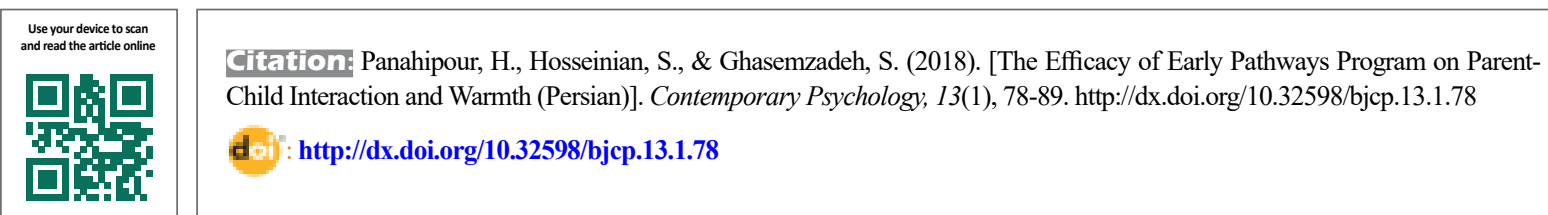

\section{() 03}

Received: 14 Nov 2017

Accepted: 10 Feb 2018

Available Online: 21 Mar 2018

Key words:

Parent-Child interac-

tion and warmth, Externalizing behavior problem, Young children, Efficacy

\section{A B S TRACT}

Objectives The current study aims to evaluate the efficacy of the Early Pathways Program on parent-child interaction and warmth in children under the age of 6 with externalizing behavior problems.

Methods The study design was pretest-posttest with the control group. A total of 21 children were chosen by available sampling method and randomly assigned to experiment (10 children) and control (11 children) groups. The experiment group participated individually in 13 sessions of intervention. The research tool was the Crowley-Spike (1983) parent-child scoring scale, and the scale of the early childhood behaviors screening.

Results Repeated measure multivariate analyses of variance revealed significant differences between and within groups. Results of the t tests (Independent and paired t tests) showed significant improvement in the experimental group on all measures with stability at 6 week follow-up.

Conclusion Finding of the study revealed the efficacy of the Early Pathways program for young children with externalized behavior problems living in poverty.

* Corresponding Author:

Simin Hosseinian, PhD.

Address: Department of Counseling, Faculty of Educational Sciences and Psychology, Alzahra University, Tehran, Iran.

Tel: +98 (21) 88615858

E-mail: hosseinain@alzahra.ac.ir 


\title{
اثربخشى برنامه همراهى بهنكًام بر ارتقاى تَرمى و تعامل والد-كودى
}

\author{
حنانه يناهىيور' • • سيمين حسينيان ' ، سوكند قاسمزاده ‘ \\ ا ب- كارشناس ارشد، كروه مشاوره، دانشكده علوم تربيتى و ووانشئاسى، دانشعاه الزهرا، تهران، ايران.

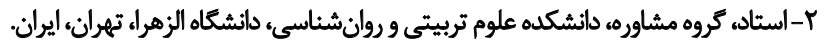

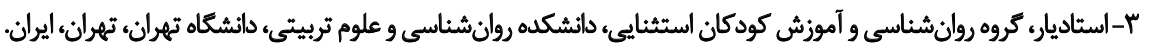

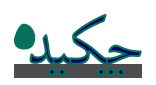

هدف اين يُّوهش به منظور بررسى اثربخشى برنامه همراهى بهنكام بر ارتقاى كرمى و تعامل والد-كودى در كودكانى انجام شده است كه

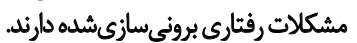

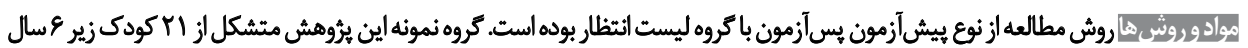

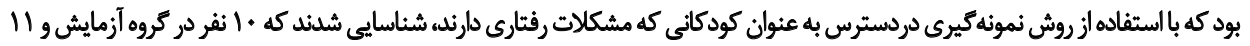

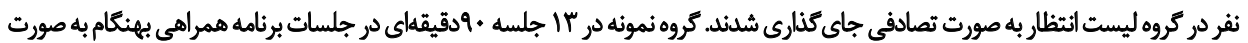

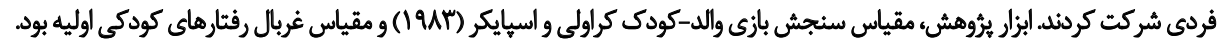

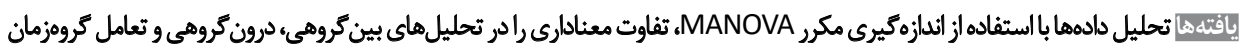

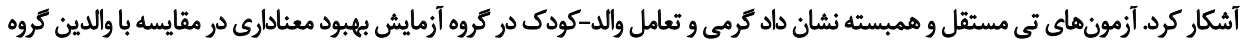
ليست ييدا كرده است.

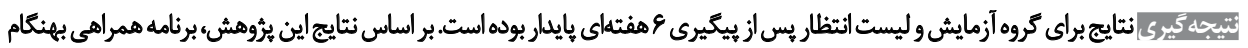

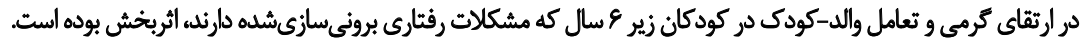

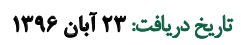

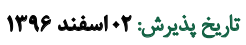

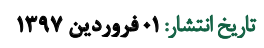

Sothlg

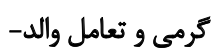

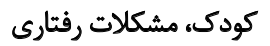

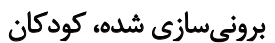
خردسال، اثربخشى شئي

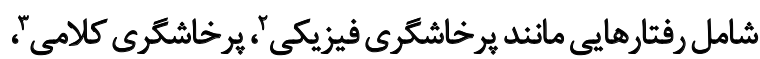

dale

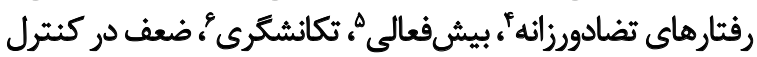

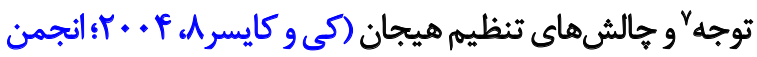

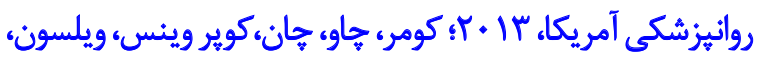

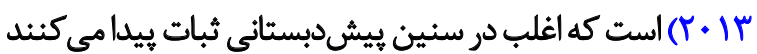

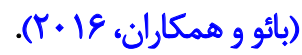

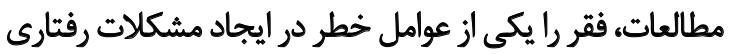

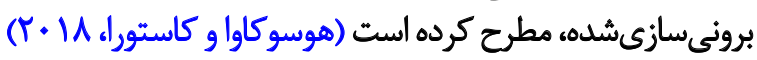
2. Physical aggression
3. Verbal aggression
4. Oppositional behavior
5. Hyperactivity
6. Impulsivity
7. Weak attention control
8. Qi \& Kaiser

1. Externalized behavior

تحقيات نشان مي دهد · ا تا • ب درصد كودكان (r تا ه ساله)

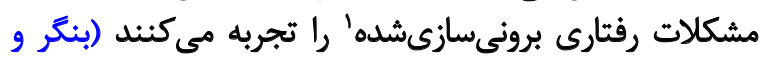

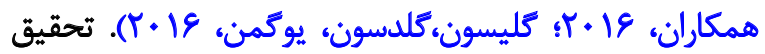

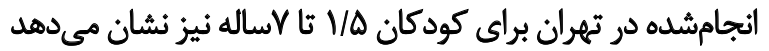

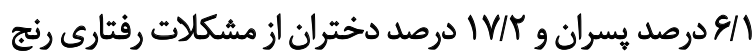

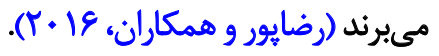

مشكلات رفتارى برونى سازى شدهبه كروهى از مشكلات رفتارى

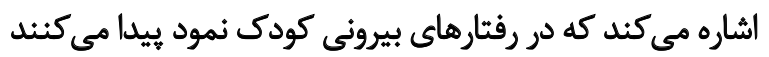

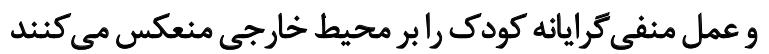

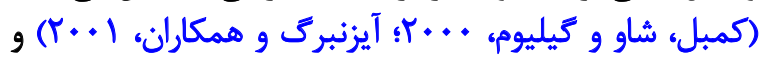

$$
\text { ㄷ. }
$$

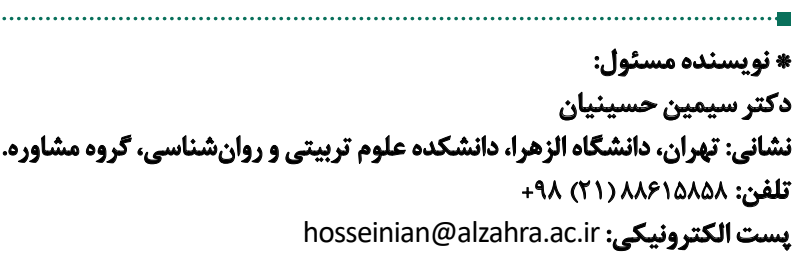


خانوادههايى كه رابطه والد-كودى قوى بترى دارئد در مواجهه

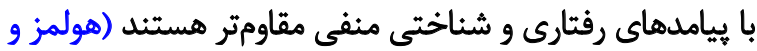

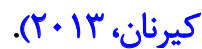

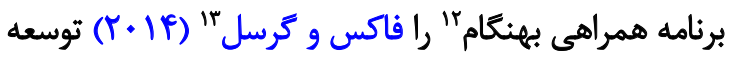

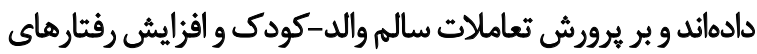

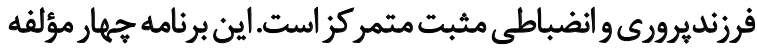

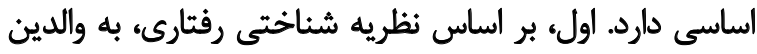

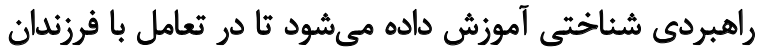

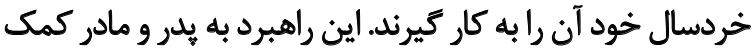

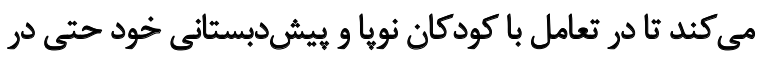

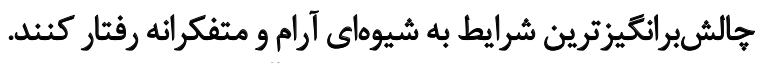

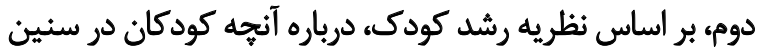

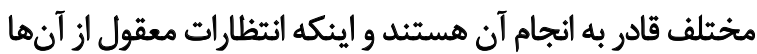

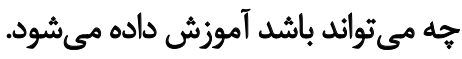

سوم، روشهاى مؤثر براى تقويت رفتارهاى مناسب و مثبت بإيت

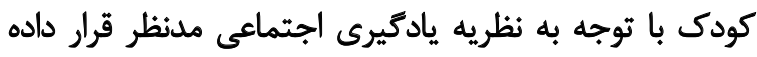

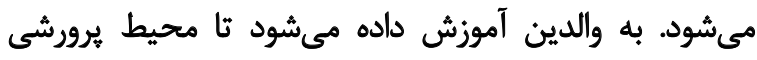

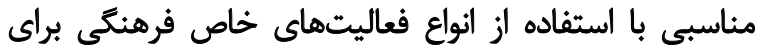

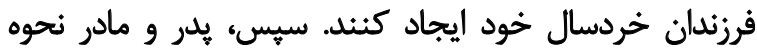

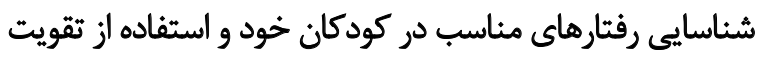

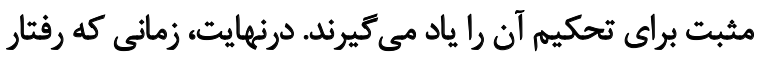

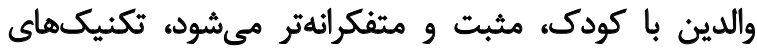

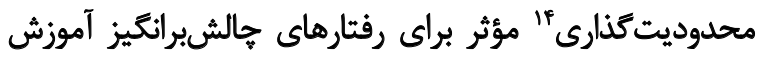

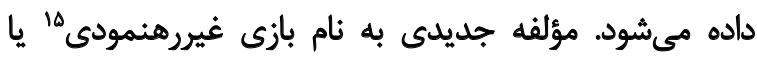

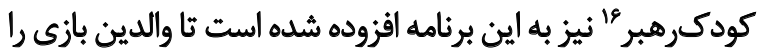

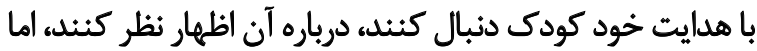
سؤالى نير سند و سعى نكنيد بازى راه راهدايت كنيند (فاكس، كرسل،

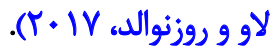

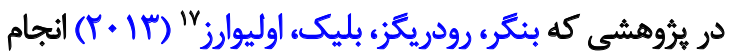

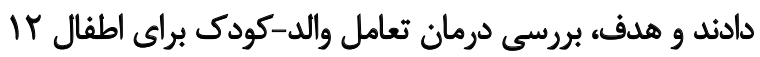

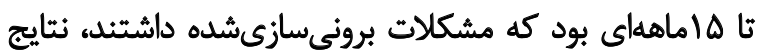

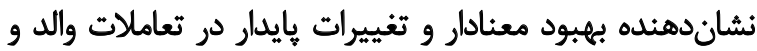

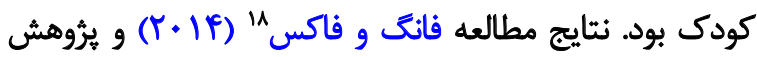

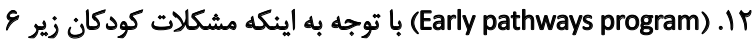

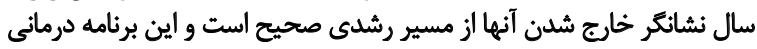

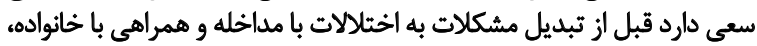

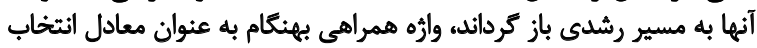

13. Fox \& Gresl

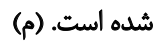

14. Limit setting

15. Non directive play

16. Child-led play

17. Banger, Rodriguez, Blake, Olivarez

18. Fung, Fox
و با توجه به نقش كيفيت روابط والد-كودى د در بايدارى اين

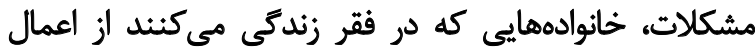

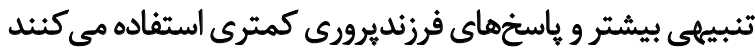

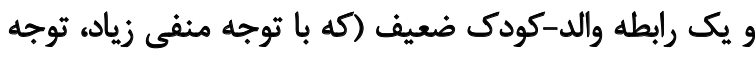

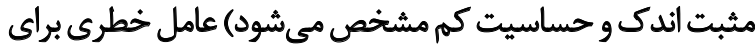

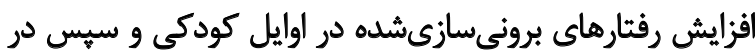

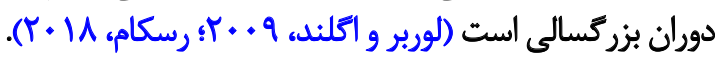
كرمى والدينى " يكى از مهمترين ابعاد مراقبتى است كه تقريباً

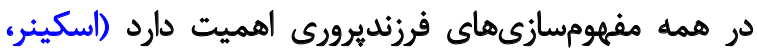

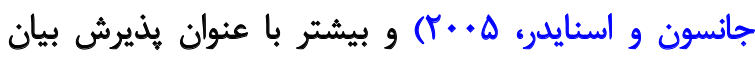

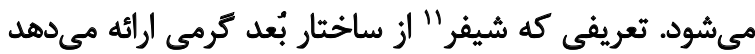

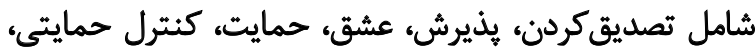

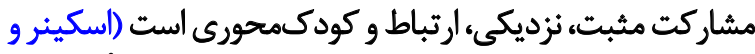

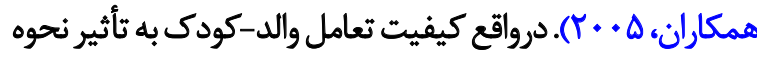

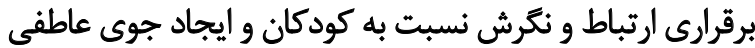

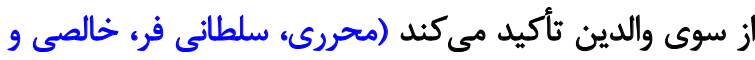

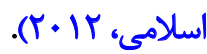

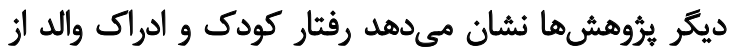

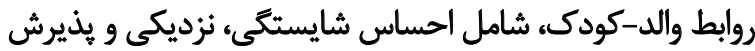

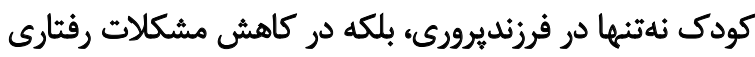

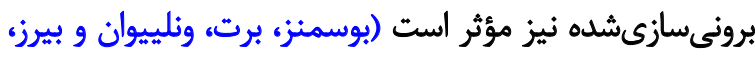

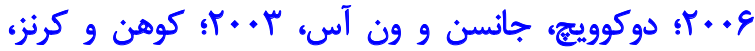

.$(T \cdot 1 \mathrm{~V}$

كودان، الس شايستكى والدين با وقوع رفتارهاى برونىسازي إشده

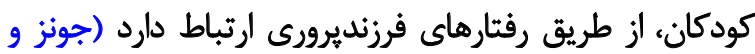

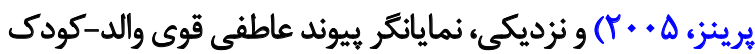

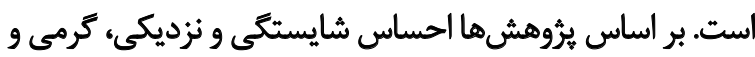

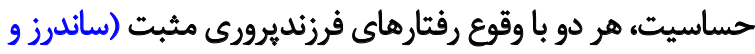

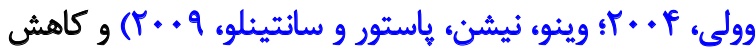

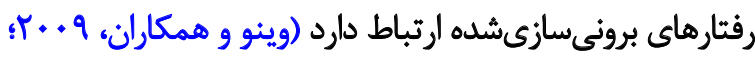

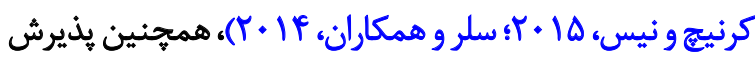

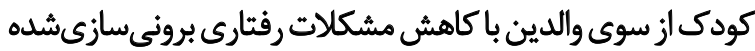

$$
\text { مرتبط است (رانر و بريتنر، ب. +. (Y). }
$$

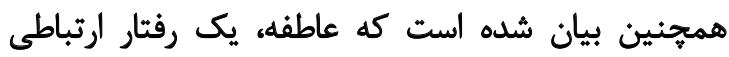

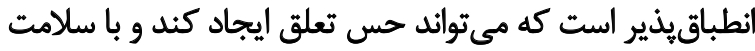

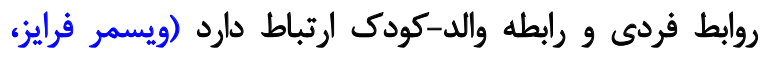

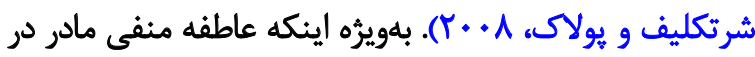

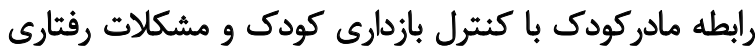

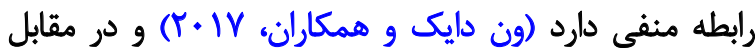

9. Parent-child interaction

10. Parental warmth

11. Schaefer 
جدولا. خلاصهاي ازز محتواي جلسات آموزشى

\begin{tabular}{|c|c|}
\hline موضوعات & جلسه \\
\hline معرفى برنامه همراهى بهئكام، تهيه اهداف درمانى اوليه، نيازسنجى از كودى و خانواده و بررسى منابع حمايتى & اول \\
\hline 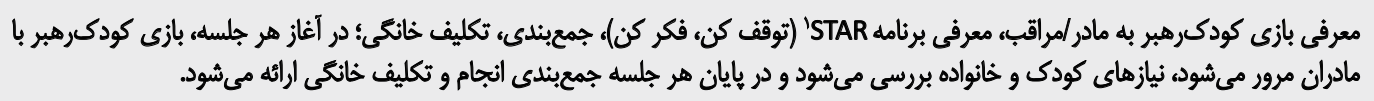 & دوק \\
\hline معرفى يالان رفتار، بحث درباره رفتار (رفتار جيست و جه جيزهايى در آن نقش دارد) & سوم \\
\hline بحث درباره جرخههاى رفتارى، مرور برنامه ذهنى STAR ( توقف كن، فكر كن و بعد سؤال كن) & جهارم \\
\hline بحث درباره رشد كودك و اثتظارات والدين، مرور برئامه ذهنى STAR (توقف كن، فكر كن، سؤال كن و سيس ياسخ بده) & بنجم: \\
\hline 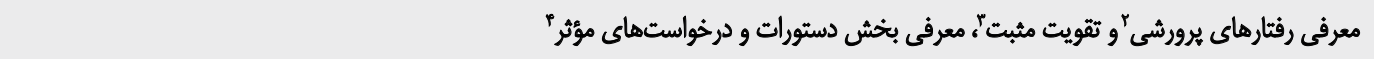 & 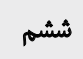 \\
\hline آموزش ايجاد روتين در خائه، هعرفى ائضباط، شناسايى رفتارهاى هالشى و راهبرد أضضباطى & مiهم \\
\hline أموزش هدايت مجددة و بي توجهى? أموزش ييامدهاي طبيعى v & هشتم \\
\hline آموزش محرومشازىى، آغاز بحث درباره يايان درمان & i \\
\hline
\end{tabular}

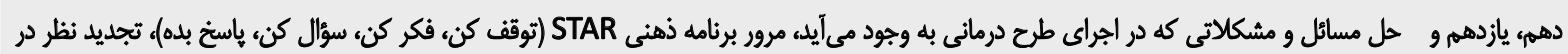

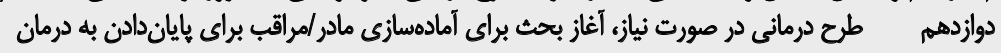

سيزدهم حل مسائل و مشكلاتى كه در اجراى طرح درمانى به وجود مى أيل، بحث درباره ماندكارى فوايد درمان با والدين، نوشت كزارش نهايى

دوفصلنامه وإنشناسى معاصر

1. Stop, Think, Ask, React

2. Nurturing

3. Positive reinforcement

4. Effective requests

يثوهش شامل تمام كودكان زير \& سال خانواددار با شرايط

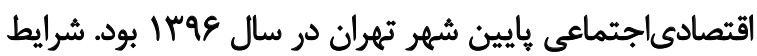

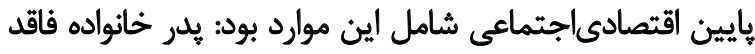

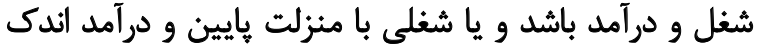

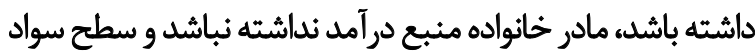

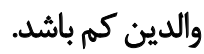

در اين يُروهش ابتدا از معاونت بهداشت شمال غرب تهران و و

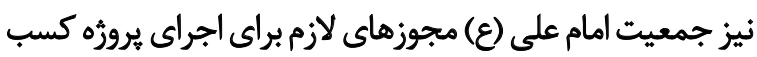

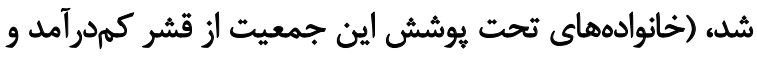

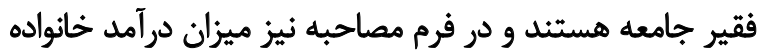

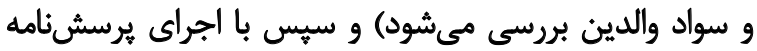

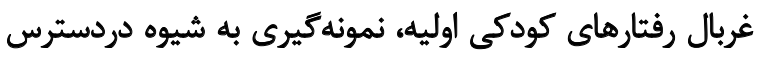

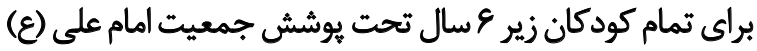

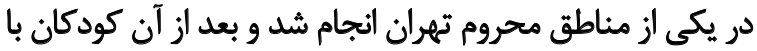

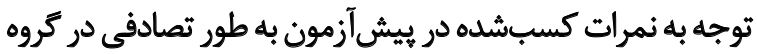

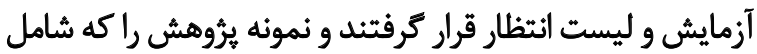

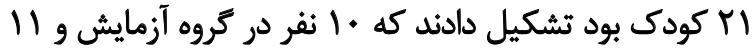
نفر در ليست انتظار قرار ترفتند.
5. Redirection

6. Ignoring

7. Natural consequences

8. Time out

كرسل، فاكس و فليشمن 19 (F) (Y) نيز در بروسى اثربخشى

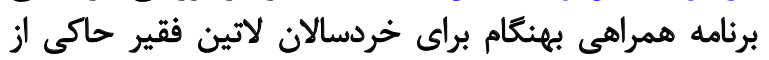
افزايش بهبود روابط والد-كودك در ميان اين كودكان بودي

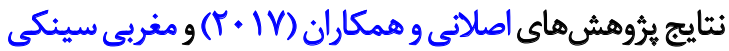

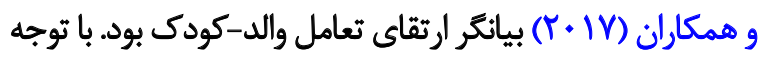

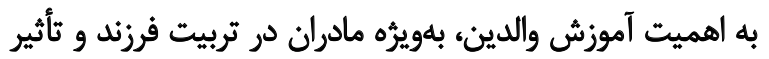

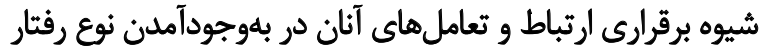

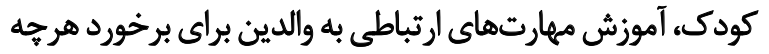

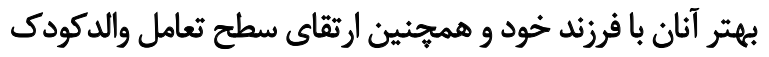

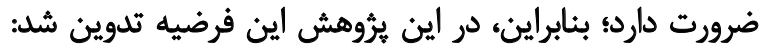

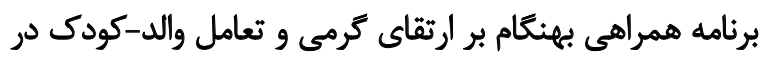

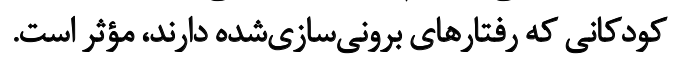

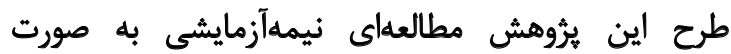

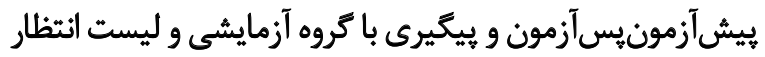

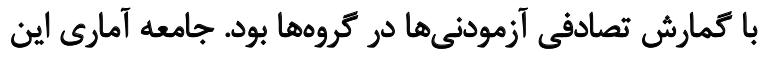

19. Gresl, Fox, Fleischmann 
مشخص شد والدين در درى يرسشنامه مشكلى نداشتند.

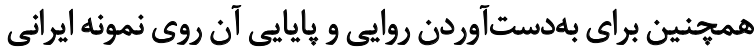

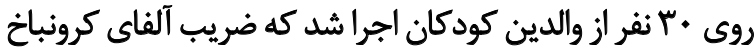

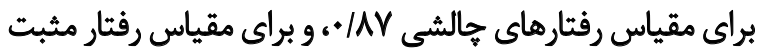

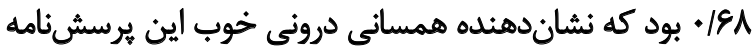

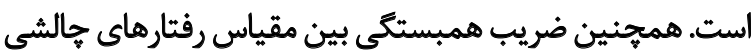

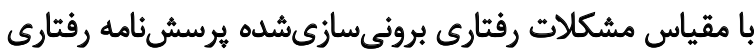

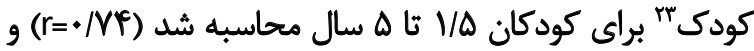

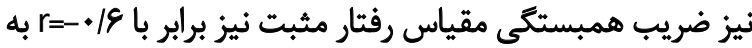

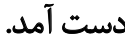

\section{يرسش بامه سنجش بازى والد-كودى}

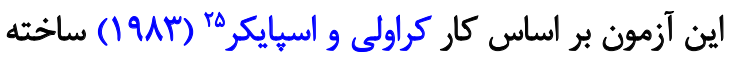

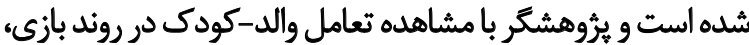

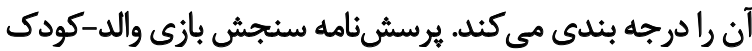

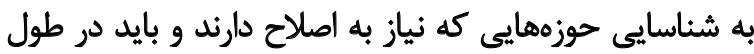

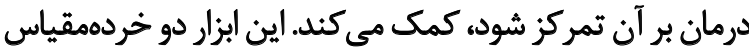

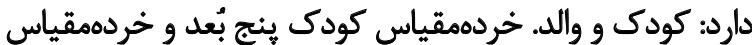

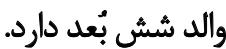

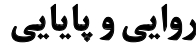

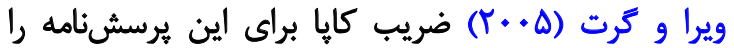

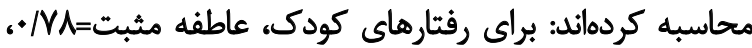

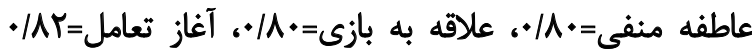

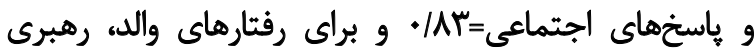

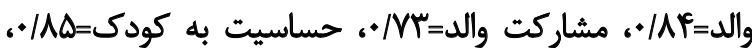

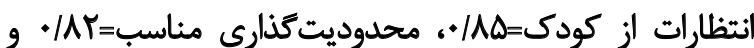

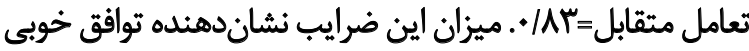

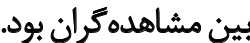

ضريب آلفا براي اين نمونه در خردهمقياس رفتار كودى

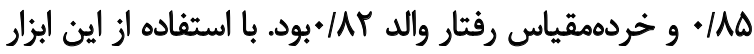

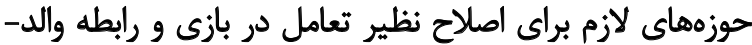

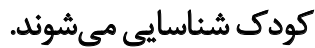

اين يرسشنامه نيز براي اولينبار در ايران در اين يرؤهش اجرا

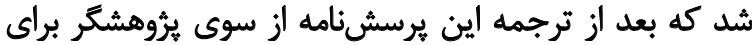

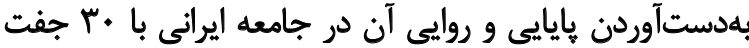

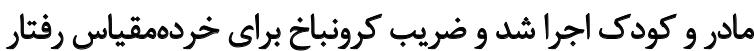

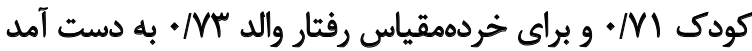
كه نشاندهنده همسانى درونى مطلوبى است.

23. The Child Behavior Checklist ( $\mathrm{CBCL}$ ) 24. Parent Child Play Assessment (PCPA) 25. Crawley, Spiker
در ابتدا كروه آزمايش بان بات نفر بود كه قبل از آغاز جلسات

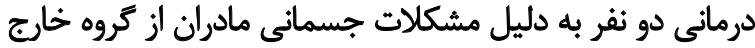

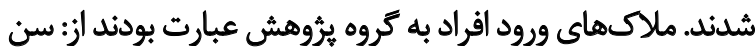

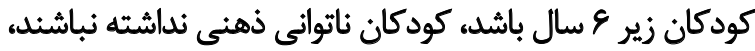

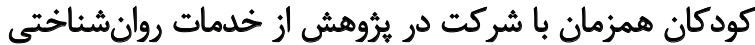

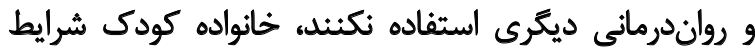

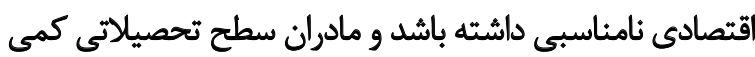

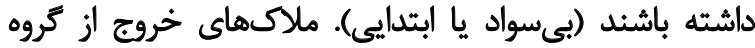

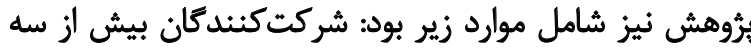

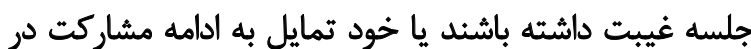
يُّورهش نداشته باشُند.

شركت كنندكان در با جلسه • ودقيقهاى به صورت فردى

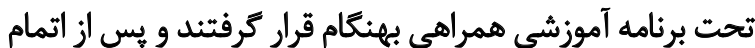

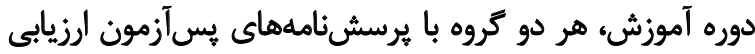

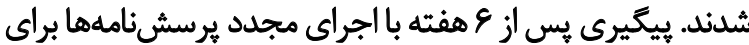

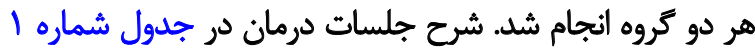

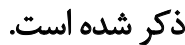

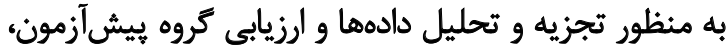

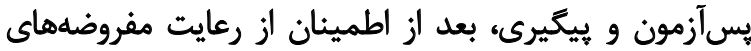

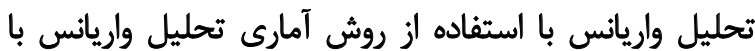

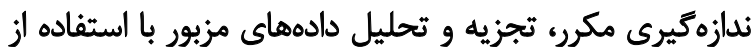

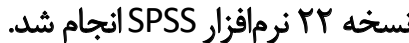

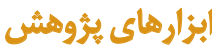

يرسشنامه غربال رفتارهاى كودكى اوليه بـ (هولتز و فاكس،

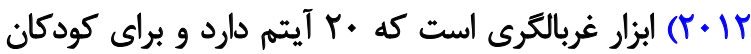

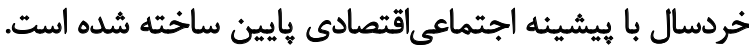

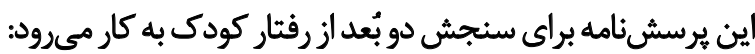

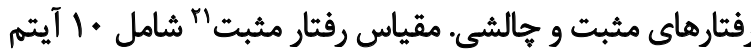

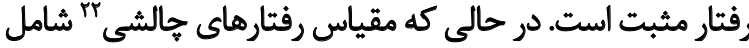
• آيتم رفتار حالشى است.

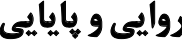

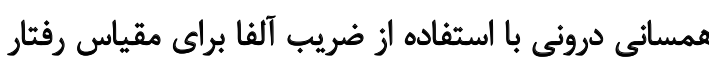

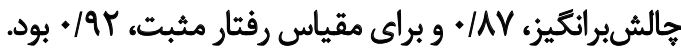

اين برسشنامه براي اولينبار در ايران، در اين يثوهش اجراشده

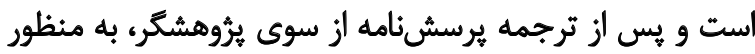

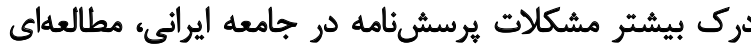

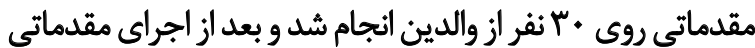

20. Early Childhood Behavior Screen (ECBS)

21. Positive Behavior Scale (PBS)

22. Challenging Brhavior Scale (CBS) 
جدول ז. آمارههاي توصيفى (ميانكين و انحراف استاندارد) كروه آزمايشى و ليست انتظار

\begin{tabular}{|c|c|c|c|c|c|c|}
\hline \multicolumn{2}{|c|}{ هو درصد فاصله الطمينان } & \multirow{2}{*}{ انحراف استاندارد } & \multirow{2}{*}{ مياتكين } & \multirow{2}{*}{ زمان } & \multirow{2}{*}{ كروه } & \multirow{2}{*}{ مقياس } \\
\hline حد بالا & حد بايين & & & & & \\
\hline Ir/u & $1 \cdot / M 1$ & .188 & $11 / 8$ & نييش آزانهون & & \multirow{6}{*}{ كرمى و تعامل والد-كودى } \\
\hline IV/9Y & IEMT &.$/ 4 T$ & $|v|$ & يس آزهون & آزمايش & \\
\hline $19 / 91$ & $W \cdot A$ & $. / 4+$ & 19 & ريكيرى & & \\
\hline 1.181 & $N \cdot P$ & 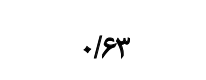 & $q / r e$ & ييش آزمون & & \\
\hline 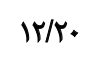 & $1 \cdot / \Delta r$ & $\cdot / 4$ & W/re & يسأزمون & ليست أتنظار & \\
\hline Ir/M & W/4a & $\cdot|\varphi|$ & Ir/me & بيكيرى & & \\
\hline
\end{tabular}

جدول T. ميانكينهاي برآورشده بين كروهى براى متغير كرمى و تعامل والد-كودى

\begin{tabular}{|c|c|c|c|c|c|}
\hline \multicolumn{2}{|c|}{ ه9 درصد فاصله اطمينان } & \multirow{2}{*}{ انحراف استاندارد } & \multirow{2}{*}{ مياتكين } & \multirow{2}{*}{ كروه } & \multirow{2}{*}{ متغير } \\
\hline حد بالا & هد بايين & & & & \\
\hline IENA & $1 f / 9$. &.$/ 4 F$ & IQ/Aץ & أزمايش & 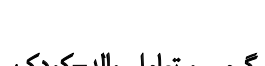 \\
\hline IV/DF & q/V &.$/ 4 T$ & 1.189 & ليست انتظار & ק \\
\hline
\end{tabular}

دوفصلنامه روانشناسى معاصر

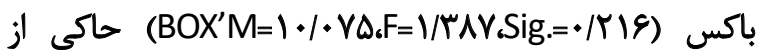

Latẹ:

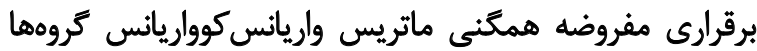

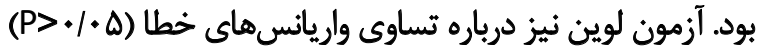

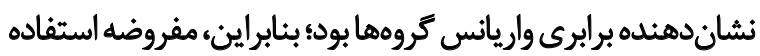

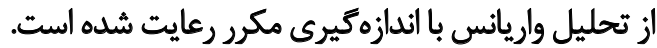

شاخص هاي توصيفي مقياس كرمي و تعامل والد-كودك در

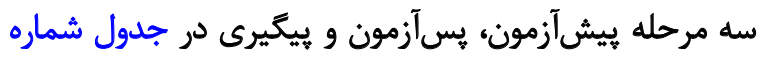

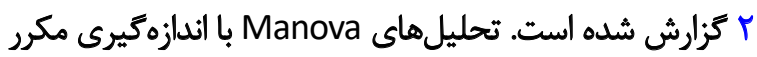

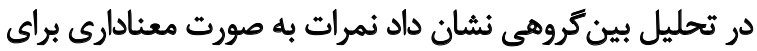

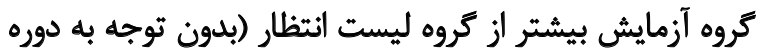

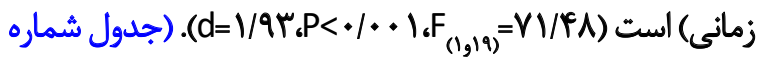

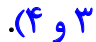

تحليل هاى درون كروهى نيز حاكى از آن است كه نمرات در اين

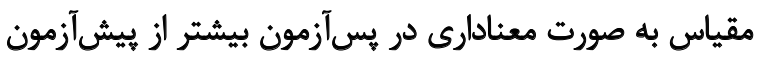

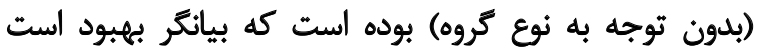

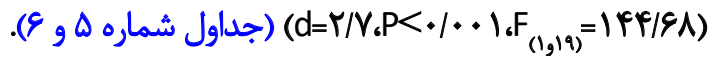
همجينين جداول شماره V و 1 نيز بيانگر تعامل معنادار بين

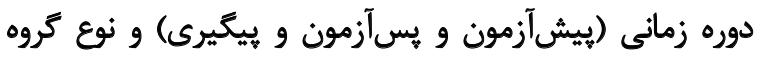

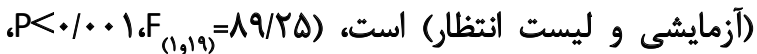
(d=1/1)

ميانكين سنى كودكان در زروه آزمايش f أن سال با انحراف

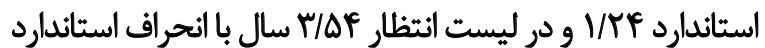

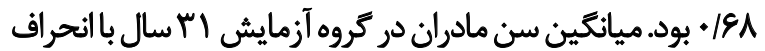

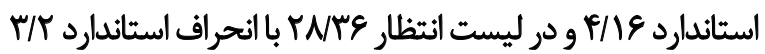

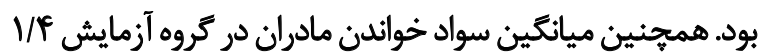

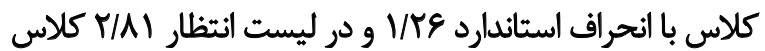

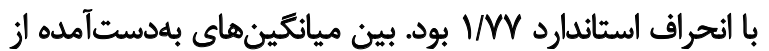

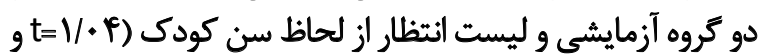

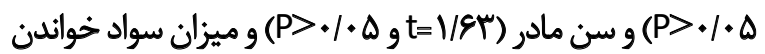
مادر (P> تفاوت معنى دارى وجود نداشت. براي بررسي همكنى واريانسهاي درون مروهى از آزمون

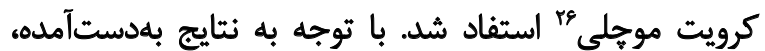

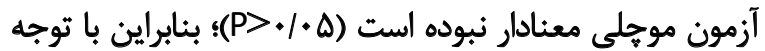

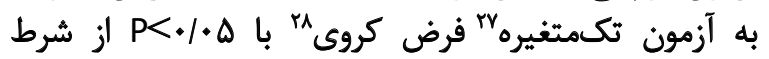
همسانى واريانسهاى درون

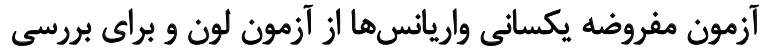

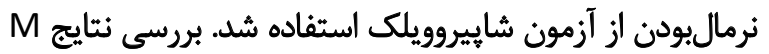

براى تحليلهاي اضافي تعامل به دليل وجود دو كروهـ از آزمون 
جدول F. نتايج آنواي بين كروهى تكمتغيرى براي متغير كرمى و تعامل والد-كودى

\begin{tabular}{|c|c|c|c|c|c|c|c|c|c|}
\hline توان آزمون & d & مجذور اتا & Sig. & $\mathbf{F}$ & Ms & df & Ss & متغير & منبع \\
\hline 1 & V/a & . $/ 9$ &.$/ \ldots 1$ & $V h / F A$ & $r \mid q / F \lambda$ & 1 & $r r / q 4$ & كرمى و تعامل & كروه \\
\hline & & & & & $\Delta / N G$ & 19 & $1 . r / \pi$ & & خطا \\
\hline
\end{tabular}

دوفصلنامه روانشناسي معاصر

مجموع مجذورات: Ss درجه آزادى: df، ميانكين مجذورات: Ms، اندازه اثر كوهن: d d d جدول هـ ميانكينهاى برآوردشده درون كروهى براى متغير كرمى و تعامل والد-كودى

\begin{tabular}{|c|c|c|c|c|c|}
\hline \multicolumn{2}{|c|}{ فاصله اطمينان } & \multirow{2}{*}{ انحراف استاندارد } & \multirow{2}{*}{ مياتكين } & \multirow{2}{*}{ زمان } & \multirow{2}{*}{ متغير } \\
\hline حد بالا & حد بايين & & & & \\
\hline $11 / 4 \pi$ & v/ar &.$/ 2 a$ & $1 . / 4 A$ & ميش أزمون & \\
\hline $16 / 48$ & $I r / A$ &.$/ r V$ & $\mid r / \Delta A$ & يس أزمون & كرمى و تعامل والد-كودى \\
\hline$|g / F|$ & $10 / .+$ &.$/ \pi$ & $\mid Q / 9 A$ & ييكيرى & \\
\hline
\end{tabular}

دوفصلنامه ووانشناسى معاصر

جدول \&. نتايج آنواي درون كروهى تكمتغيرى براى متغير كرمى و تعامل والد-كودى

\begin{tabular}{|c|c|c|c|c|c|c|c|c|c|}
\hline أزمون & كوهن (d) أندازه اثر & مجذور اتا & Sig. & $\mathbf{F}$ & Ms & df & Ss & متّير & منيع \\
\hline 1 & $r / V$ &.$/ M$ & $+1+\infty+1$ & IfF/gA & $r A M / T Y$ & 1 & YAT/TV & ، و تعامل & زمان \\
\hline & & & & & $1 / 90$ & 19 & $r / T$. & & خُطا \\
\hline
\end{tabular}

دوفصلنامه لوانشناسى معاصر

هجموع مجذورات: SS درجه آزادي: df، ميانكين مجذورات: Ms، اندازه اثر كوهن: d d d

ليست انتظار حاكى از آن است كه نمرات به صورت معنادارى بين

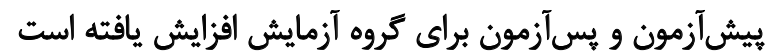

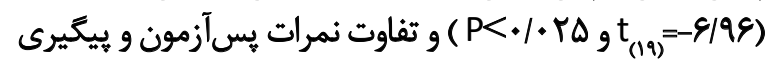
كروه آزمايش معنادار است. (P< (P)
تى مستقل استفاده شد. اين آزمون نشان داد تفاوت معنادارى

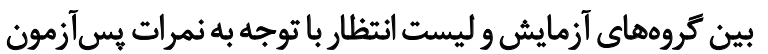

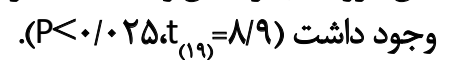
همجنين نتايج تحليل تى همبسته براى نمرات اين مقياس بين

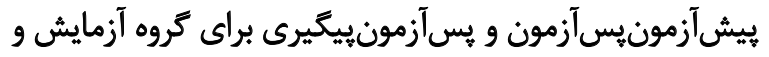

جدول Y. ميانكينهاى برآوردشده تعامل كرومزمان

\begin{tabular}{|c|c|c|c|c|c|}
\hline \multicolumn{2}{|c|}{ فاصله اطمينان } & \multirow{2}{*}{ انحراف استاندارد } & \multirow{2}{*}{ مياتكين } & \multirow{2}{*}{ زمان } & \multirow{2}{*}{ كروه } \\
\hline حد بالا & حد بايين & & & & \\
\hline$r \Delta / T Y$ & IVAr & $V / r V$ & $r T / \Delta$ & ييشآزمون & \\
\hline $\mid \theta / \cdot f$ & $11 / v a$ & $\cdot N A$ & $\mid w / f$ & بس آزهون & آزمايش \\
\hline $1 r / F V$ & $1 . / \Delta Y$ & 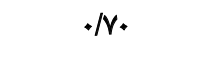 & ir & بيكيرى & \\
\hline$\Gamma \varphi / \Delta \Delta$ & $19 / 4 P$ & $|/ r|$ & M & ييش آزمون & \\
\hline$r \Delta / r V$ & $r / r r$ & $\cdot M^{e}$ & $r r / q$. & يسآزمون & ليست انتظار \\
\hline$r / / r$ & $T \cdot / T T$ & $.19 V$ & $r M / N$ & بيكيرى & \\
\hline
\end{tabular}


جدول A ـ نتايج آنواي تعامل كروهزمان تكمتغيرى

\begin{tabular}{|c|c|c|c|c|c|c|c|c|}
\hline توان آزمون & اندازه اثر كوهن (d) & مجذور اتا & Sig. & $\mathbf{F}$ & Ms & df & Ss & هنبع \\
\hline \multirow[t]{2}{*}{1} & $V / \&$ & $\cdot / \Delta V$ & $.1+\infty 1$ & $r \Delta / 19$ & $\Delta+/ N$ & 1 & $\Delta+/ N$ & كروهزمان \\
\hline & & & & & $1 / 9 \Delta$ & 19 & $r V / T$ & خطا \\
\hline
\end{tabular}

دوفصلنامه وانشناسى معاصر

مجموع مجذورات: SS درجه آزادى: df، ميانكين مجذورات: MS، اندازه اثر كوهن: df

ابراز نظرهاي مثبت مادر در بازى موجب افزرايش عاطفه مثبت

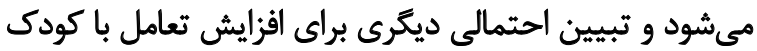
فر اهم هي كنيد.

يُروهشها نشان دادهاند نهتنها رفتار كودك، بلكه ادراى

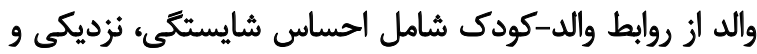

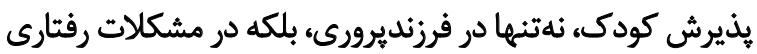

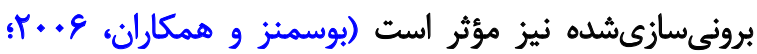

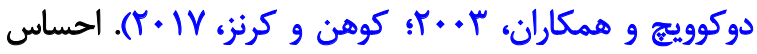

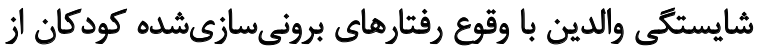

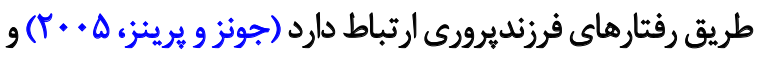
نزديكى نمايانگر ييوند عاطفى قوى والد-كودى است فرون.

همجينين احساس شايستكي و نزديكي هر دو باوقوع رفتتارهاي

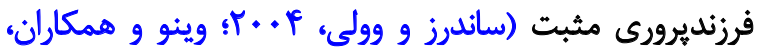

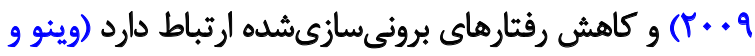

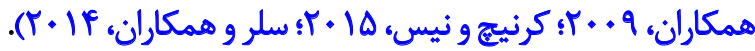

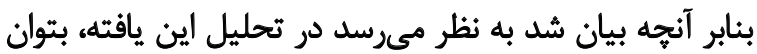

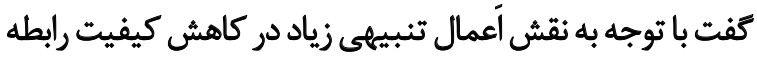

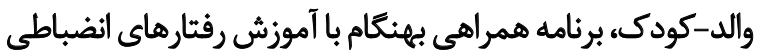

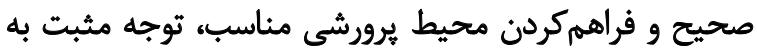

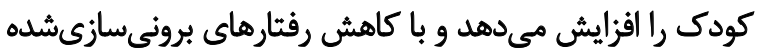

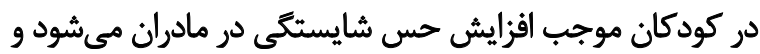

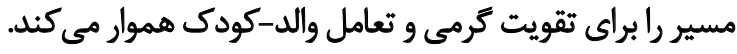
از جمله محدوديتهاي اين مطالعه، حجم بإيين نمونه بود.

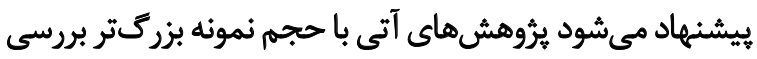

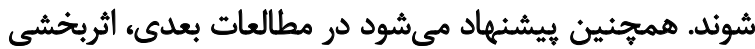

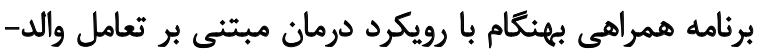

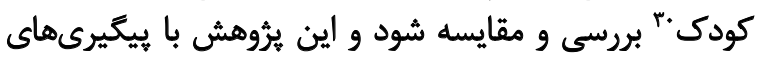

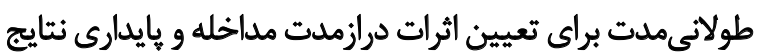
تكرار شود.

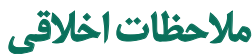

بيروى از الصول الخالاق بوُوهش

يُروهش حاضر بر اساس كدهاى اخلاق حرفهاى روانشناسان

30. Parent-Child Interaction Therapy (PCIT) $\stackrel{*}{*}$

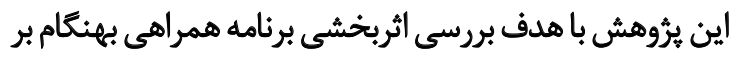

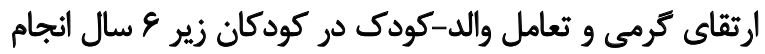

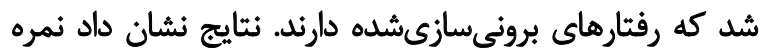

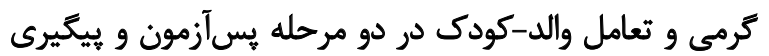

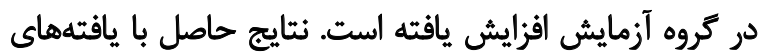

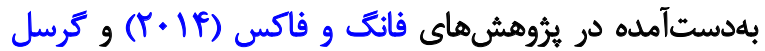

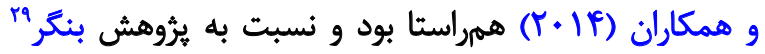

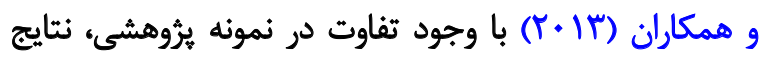
مشابهى حاصل شده است.

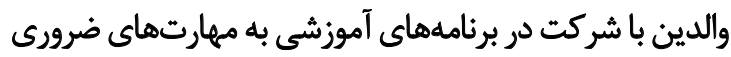

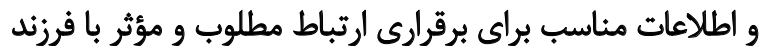

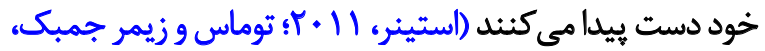

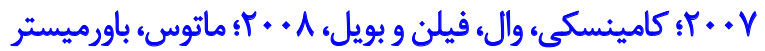

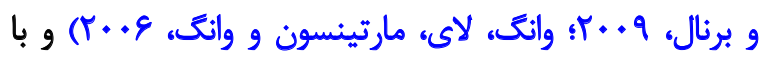

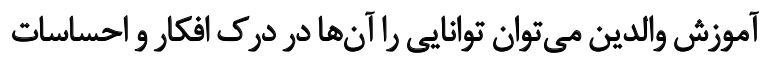

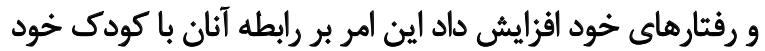

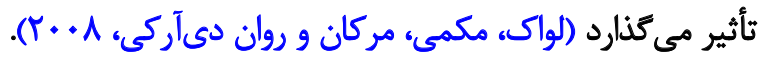

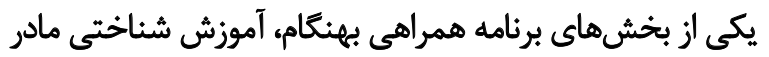
در بررسى افكار و احساسات خود از طريق فرئ فرايند

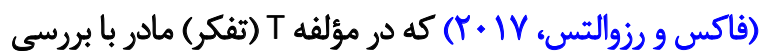

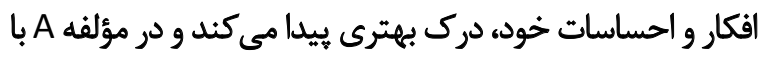

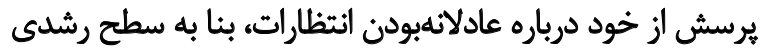

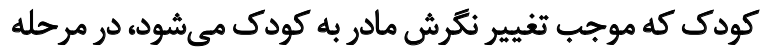
بعل مى تواند پاسخ مناسبترى موج ارائه كند. فاكس و رزوالتس (Y (Y) مي كويند بازى كودكر هبر رابطه

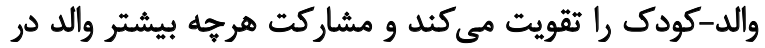
بازى موجب افزايش كيفيت تعامل والد-كودك مي وشود (رانسن،

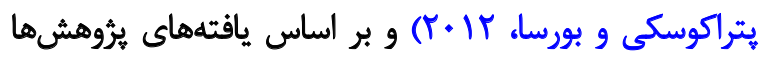
عاطفه يك رفتار ارتباطى انطباق يذير است كه مي ثواند حس تعلق

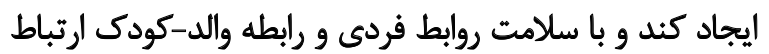

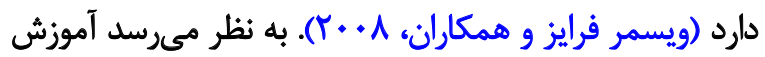

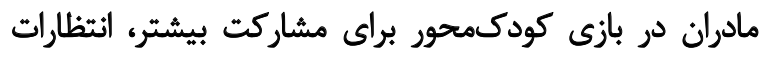

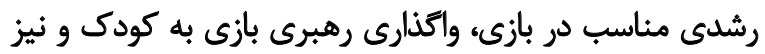

29. Bagner 
و مشاوران انجام شده است. براى اجراى ملاحظات مذكور،

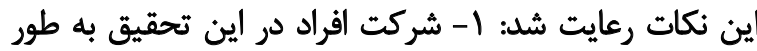

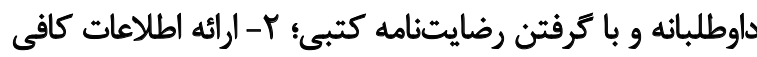

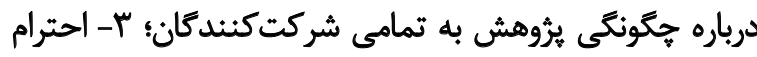

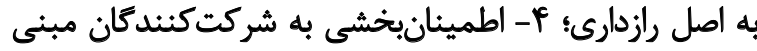

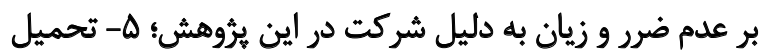

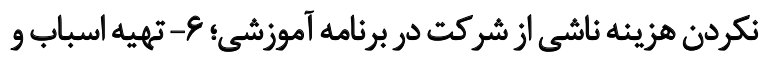

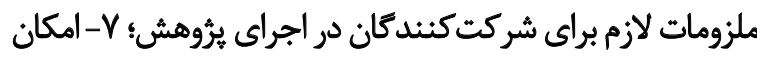

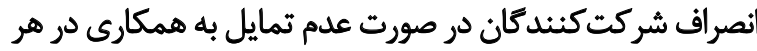

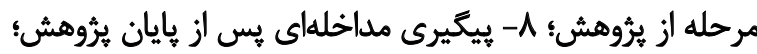

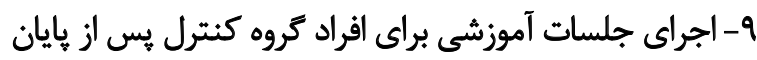

$$
\text { مامي مالي }
$$

يُوهش حاضر حامى مالى نداشته و با هزينه نويسندكان انجام

$$
\text { شده است. }
$$

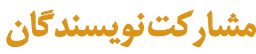

مشاركت نويسندكان به شرح زير است: نظارت و راهنماييى و

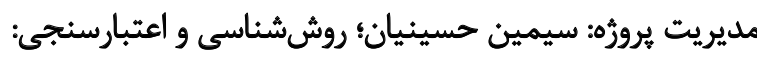

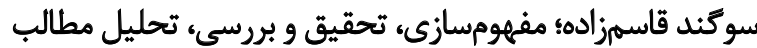

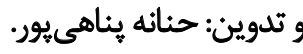

$$
\text { تعارض مثأع }
$$

بنا به اظهار نويسندكان اين مقاله تعارض منافع نداشته است.

$$
\text { سياسكُّز أرى }
$$

از همكارى صميمانه جمعيت امام على (ع) تشكر مى كنيه. 
References

American Psychiatric Association. (2013). Diagnostic and statistical manual of mental disorders ( $5^{\text {th }}$ Ed.). Washington, D.C.: American Psychiatric Association.

Aslani, kh., varasteh, M., Amanelahi, M. (2017). [Effectiveness of positive parenting program training on parent-child interaction quality (Persian)]. Counseling Culture and Psychotherapy, 7(28), 183-201.

Bagner, D. M., Coxe, S., Hungerford, G. M., Garcia, D., Barroso, N. E., Hernandez, J., et al. (2016). Behavioral parent training in infancy: A window of opportunity for high-risk families. Journal of Abnormal Child Psychology, 44(5), 901-12. [DOI:10.1007/ s10802-015-0089-5] [PMID] [PMCID]

Bagner, D. M., Rodríguez, G. M., Blake, C. A., \& Rosa-Olivares, J. (2013) Home-based preventive parenting intervention for at-risk infants and their families: An open trial. Cognitive and Behavioral Practice, 20(3) 334-48. [DOI:10.1016/j.cbpra.2012.08.001] [PMID] [PMCID]

Bao, P., Jing, J., Jin, Y., Hu, X., Liu, B., \& Hu, M. (2016). Trajectories and the influencing factors of behavior problems in preschool children: $A$ longitudinal study in Guangzhou, China. BMC Psychiatry, 16(1), 178 [DOI:10.1186/s12888-016-0864-z] [PMID] [PMCID]

Biglan, A., Mrazek, P.J., Carnine, D., \& Flay, B.R. (2003). The integration of research and practice in the prevention of youth problem behaviors. American Psychologist, 58(6-7), 433-40. [DOI:10.1037/0003066X.58.6-7.433] [PMID]

Bosmans, G., Braet, C., Van Leeuwen, K., \& Beyers, W. (2006). Do parenting behaviors predict externalizing behavior in adolescence, or is attachment the neglected $3^{\text {rd }}$ factor? Journal of Youth and Adolescence, 35(3), 373-83. [DOI:10.1007/s10964-005-9026-1]

Campbell, S. B., Shaw, D. S., \& Gilliom, M. (2000). Early externalizing behavior problems: Toddlers and preschoolers at risk for later maladjustment. Development and psychopathology, 12(3), 467-88. [DOI:10.1017/ S0954579400003114]

Comer, J. S., Chow, C., Chan, P. T., Cooper-Vince, C., \& Wilson, L. A. (2013) Psychosocial treatment efficacy for disruptive behavior problems in very young children: A meta-analytic examination. Journal of the American Academy of Child \& Adolescent Psychiatry, 52(1), 26-36. [DOI:10.1016/j. jaac.2012.10.001.]

Crawley, S. B., \& Spiker, D. (1983). Mother-child interactions involving twoyear-olds with Down syndrome: A look at individual differences. Child Development, 54, 1312-23.

Crnic, K., \& Neece, C. L. (2015). Illness and disability. In R. M. Lerner (Eds.) Handbook of child psychology and developmental science. Hoboken: Wiley. [DOI:10.1002/9781118963418.childpsy308]

Deković, M., Janssens, J. M., \& Van As, N. M. (2003). Family predictors of antisocial behavior in adolescence. Family Process, 42(2), 223-35. [DOI:10.1111/j.1545-5300.2003.42203.x]

Eisenberg, N., Cumberland, A., Spinrad, T. L., Fabes, R. A., Shepard, S. A. Reiser, M., et al. (2001). The relations of regulation and emotionality to children's externalizing and internalizing problem behavior. Child Development, 72(4), 1112-34. [DOI:10.1111/1467-8624.00337]

Fox, R. A., Gresl, B. L., Love, J. R., \& Rosenwald, M. M. (2017). Early path ways: Home-based mental health services for very young children in poverty $\left(2^{\text {nd }} E d.\right)$. Wisconsin: Marquette University Press.

Frick, P. J., \& Matlasz, T. M. (2018). Disruptive, impulse-control, and conduct disorders. In American Psychiatric Association (Eds.), Developmental Pathways to Disruptive, Impulse-Control and Conduct Disorders (pp.
3-20). Philadelphia: American Psychiatric Association. [DOI:10.1176/ appi.books.9780890425596.dsm15]

Fung, M. P., \& Fox, R. A. (2014). The culturally-adapted Early Pathways program for young Latino children in poverty: A randomized controlled trial. Journal of Latina/o Psychology, 2(3), 131-45. [DOI:10.1037/lat0000019]

Gleason, M. M., Goldson, E., Yogman, M. W. (2016). Council on early childhood, committee on psychosocial aspects of child and family health section on developmental and behavioral pediatrics. Addressing early childhood emotional and behavioral problems. Pediatrics. 138(6), e20163025. [DOI:10.1542/peds.2016-3025] [PMID]

Gresl, B. L., Fox, R. A., \& Fleischmann, A. (2014). Home-based parent-child therapy in low-income African American, Caucasian, and Latino families: A comparative examination of treatment outcomes. Child \& Family Behavior Therapy, 36(1), 33-50. [DOI:10.1080/07317107.2014.878193]

Holtz, C. A., \& Fox, R. A. (2012). Behavior problems in young children from low-income families: The development of a new screening tool. Infant Mental Health Journal, 33(1), 82-94. [DOI:10.1002/ imhj.20341]

Holmes, J., \& Kiernan, K. (2013). Persistent poverty and children's development in the early years of childhood. Policy \& Politics, 41(1), 19-42. [DOI:10.1332/030557312X645810]

Hosokawa, R., \& Katsura, T. (2018). Effect of socioeconomic status on behavioral problems from preschool to early elementary school- A Japanese longitudinal study. PLOS One, 13(5), e0197961. [DOI:10.1371/journal.pone.0197961] [PMID] [PMCID]

Jones, T. L., \& Prinz, R. J. (2005). Potential roles of parental self-efficacy in parent and child adjustment: A review. Clinical Psychology Review, 25(3), 341-63. [DOI:10.1016/j.cpr.2004.12.004] [PMID]

Kaminski, J. W., Valle, L. A., Filene, J. H., \& Boyle, C. L. (2008). A meta-analytic review of components associated with parent training program effectiveness. Journal of Abnormal Child Psychology, 36(4), 567-89. [DOI:10.1007/s10802-007-9201-9] [PMID]

Koehn, A. J. \& Kerns, K. A. (2017). Parent-child attachment: met analysis of associations with parenting behaviors in middle childhood and adolescence. Attachment \& Human Development, 20(4), 378-405. [DOI 10.1080/14616734.2017.1408131]

Levac, A. M., McMay, E., Merka, P., \& Reddon-D’Arcy, M. L. (2008). Exploring parent participation in parent training program for children's aggression: Understanding and illuminating mechanisms of change. Journal of Child and Adolescent Psychiatric Nursing, 21(2), 78-88. [DOI:10.1111/j.17446171.2008.00135.x] [PMID]

Lorber, M. F., \& Egeland, B. (2009). Infancy parenting and externalizing psychopathology from childhood through adulthood: Developmental trends. Developmental Psychology, 45(4), 909-12. [DOI:10.1037/ a0015675] [PMID] [PMCID]

Maghrebi Sinaki, H., Hassanzadeh, S., Arjmandnia, A., Khademi, M. (2016). [The effect of teaching communication skills to mothers of children with attention deficit/ hyperactivity disorder on enhancement of parentchild interaction (Persian)]. Developmental Psychology, 13(49), 57-69.

Matos, M., Bauermeister, J. J., \& Bernal, G. (2009). Parent-child interaction therapy for Puerto Rican preschool children with ADHD and behavior problems: A pilot efficacy study. Family Process, 48(2), 232-52. [DOI:10.1111/j.1545-5300.2009.01279.x]

Moharreri, F., Soltanifar, A., Khalesi, H., Eslami, N. (2012). [The evaluation of efficacy of the positive parenting for parents in order improvement of relationship with their adolescents (Persian)]. Medical Journal of Mashhad University of Medical Sciences, 55(2), 116-23. 
Movahed Abtahi, M., \& Kerns, K. A. (2017). Attachment and emotion regulation in middle childhood: Changes in affect and vagal tone during a social stress task. Attachment \& Human Development, 19(3), 221-42. [D OI:10.1080/14616734.2017.1408131]

Pourhossein, R., Habibi, M., Ashoori, A., Ghanbari, N., Riahi, Y., \& Ghodrati, S. (2015). revalence of behavioral disorders among preschool children (Persian)]. Journal of Fundamentals of Mental Health, 17(5), 234-9.

Qi, C. H., \& Kaiser, A. P. (2004). Problem behaviors of low-income children with language delays: An observation study. Journal of Speech, Language, and Hearing Research, 47, 595-609. [DOI:10. 1044/10924388(2004/046)]

Rezapour, H., Habibi, M., Ashouri, A., Ghanbari, N., Riyahi, Y., Ghodrati, S. (2015). [Prevalence of behavior disorders in preschool children (Persian)]. Journal of Fundamentals of Mental Health, 17(5), 234-9.

Rohner, R. P., \& Britner, P. A. (2002). Worldwide mental health correlates of parental acceptance-rejection: Review of cross-cultural and intra cultural evidence. Cross-Cultural Research, 36(1), 16-47. [DOI:10.1177/106 939702129146316]

Roskam, I. (2018). Externalizing behavior from early childhood to adolescence: Prediction from inhibition, language, parenting, and attachment. Development and Psychopathology, 22, 1-13. [DOI:10.1017/ S0954579418000135] [PMID]

Runcan, P. L., Petracovschi, S., \& Borca, C. (2012). The importance of play in the parent-child interaction. Procedia-Social and Behavioral Sciences, 46(2016), 795-9. [DOI:10.1016/j.sbspro.2012.05.201]

Sanders, M. R., \& Woolley, M. L. (2004). The relationship between maternal self efficacy and parenting practices: Implications for parent training. Child: Care, Health and Development, 31(1), 65-73. [DOI:10.1111/ j.1365-2214.2005.00487.x] [PMID]

Sellers, R., Harold, G. T., Elam, K., Rhoades, K. A., Potter, R., Mars, B., et al. (2014). Maternal depression and co-occurring antisocial behaviour: Testing maternal hostility and warmth as mediators of risk for offspring psychopathology. Journal of Child Psychology and Psychiatry, 55(2), 112-20. [DOI:10.1111/jcpp.12111] [PMID] [PMCID]
Skinner, E., Johnson, S., \& Snyder, T. (2005). Six Dimensions of Parenting: A Motivational Model. Parenting: Science And Practice, 2(5), 175-235 [DOI:10.1207/s15327922par0502_3]

Steiner, A. M. (2011). A strength-based approach to parent education for children with autism. Journal of Positive Behavior Interventions, 13(3), 178-90. [DOI:10.1177/1098300710384134]

Thomas, L., \& Zimmer-Gembeck, M. (2007). Behavioral outcomes of parent-child interaction therapy and triple P-Positive Parenting Program: A review and meta-analysis. Journal of Abnormal Child Psychology, 35(3), 475-95. [DOI:10.1007/s10802-007-9104-9] [PMID]

van Dijk, R., Deković, M., Bunte, T. L., Schoemaker, K., Zondervan-Zwijnenburg, M., Espy, K. A., et al. (2017). Mother-child interactions and externalizing behavior problems in preschoolers over time: Inhibitory control as a mediator. Journal of Abnormal Child Psychology, 45(8), 1503-17. [DOI:10.1007/s10802-016-0258-1] [PMID] [PMCID]

Vieno, A., Nation, M., Pastore, M., \& Santinello, M. (2009). Parenting and antisocial behavior: A model of the relationship between adolescent self-disclosure. Developmental Psychology, 6(45), 1509-19. [DOI:10.1037/a0016929] [PMID]

Viera, A. J. \& Garrett, J. M. (2005). Understanding Interobserver Agreement: The Kappa Statistic. Family Medicine, 37(5), 360-3. [PMID]

Wismer Fries, A. B., Shirtcliff, E. A., \& Pollak, S. D. (2008). Neuroendocrine dysregulation following early social deprivation in children. Developmental Psychobiology, 50(6), 588-99. [DOI:10.1002/dev.20319] [PMID] [PMCID]

Wong, S. Y., Lai, A. C., Martinson, I., \& Wong, T. K. (2006). Effects of on education program on family participation in the rehabilitation of children with developmental disability. Journal of Intellectual Disabilities, 10(2), 165-89. [DOI:10.1177/1744629506064012] [PMID] 
This Page Intentionally Left Blank 